\title{
O CONCEITO DE REFORMA PROTESTANTE NA HISTORIOGRAFIA BRASILEIRA
}

\author{
THE CONCEPT OF PROTESTANT REFORMATION IN BRAZILIAN HISTORIOGRAPHY
}

João Oliveira Ramos Neto* joao.neto@ifgoiano.edu.br

RESUMO: Este artigo é parte do resultado da nossa pesquisa de doutorado, especificamente a introdução da tese, quando trabalhamos sobre o conceito de Reforma Protestante. Usado no singular e possuidor de um juízo de valor implícito, o termo difundido na historiografia brasileira não dá conta de satisfazer a realidade. Na primeira parte, debatemos o conceito de protestantismo. $\mathrm{Na}$ segunda parte, questionamos a utilização do termo no singular para descrever um movimento plural. $\mathrm{Na}$ terceira parte, questionamos a utilização do termo reforma para descrever um movimento cismático. Concluímos com algumas sugestões.

PALAVRAS-CHAVE: Reforma Protestante, Protestantismo, Martinho Lutero, Luteranos.

ABSTRACT: This article is part of the result of our research, specifically the introduction of doctoral thesis, when we work about the concept of Protestant Reformation. Used in the singular and possessed of an implicit value judgment, the term diffused in Brazilian historiography is not enough to satisfy the reality. In the first part, we discussed the concept of Protestantism. In the second part, we question the use of the term in the singular to describe a plural movement. In the third part, we question the use of the term reform to describe a schismatic movement. We conclude with some suggestions.

KEYWORDS: Protestant Reformation, Protestantism, Martin Luther, Lutherans.

\section{Introdução}

Este artigo é parte do resultado da nossa pesquisa de doutorado, quando trabalhamos sobre o conceito de Reforma Protestante. O que a historiografia brasileira predominantemente denomina como Reforma Protestante teve início formal em 31 de outubro de 1517, quando o monge agostiniano Martinho Lutero (1483-1546) publicou 95 teses na cidade de Wittenberg, na Saxônia, atual Alemanha, contra algumas doutrinas oficiais da Igreja romana, doutrinas que ele considerava abusivas, entre elas, a das indulgências.

Há uma discussão historiográfica sobre a veracidade do relato da afixação das teses na porta da Igreja do castelo de Wittenberg por Lutero. Como não é objeto deste texto tal discussão, usaremos o termo publicação, que pressupõe uma difusão, independentemente do meio usado para tal. Fato é que, independentemente do meio utilizado para difusão, a ação questionadora do monge Martinho Lutero, iniciada formalmente com as 95 teses em

\footnotetext{
* Doutor em História pela Universidade Federal de Goiás. Realiza estágio pós-doutoral no Programa de PósGraduação em Educação da Pontifícia Universidade Católica de Goiás. É professor do Ensino Básico, Técnico e Tecnológico do Instituto Federal Goiano e do Mestrado Profissional em Ensino para a Educação Básica.
}

Hist. R., Goiânia, v. 24, n. 1, p. 206-217, jan./abr. 2019 
Wittenberg, estendeu-se posteriormente para a discussão de diversos outros temas teológicos, e abarcou outras cidades, causando conflitos teológicos irreversíveis - entre as ideias dele mesmo, a de seus seguidores e a de outros líderes novos que sugiram - com a doutrina oficial da Igreja romana, bem como conflitos políticos com o papa.

Como desses conflitos resultaram uma nova religiosidade cristã instituída $e$ separada em definitivo da Igreja Católica - denominada de protestantismo - trata-se de um cisma na Cristandade ocidental. O problema é que, apesar de a historiografia internacional especificamente a de língua inglesa - posterior ter feito uma revisão, a historiografia disponível - ou, ainda produzida - em língua portuguesa segue a historiografia alemã do século XVIII, positivista, que passou a denominar o cisma de Reforma Protestante. Como veremos, termo imbuído de um juízo de valor que, no contexto positivista, justificava-se pois pensava-se tratar-se de uma evolução histórica - já que o cristianismo anterior, medieval e, por isso, tido como inferior, era substituído por uma nova forma de cristianismo, moderno, mais racional e, sobretudo, germânico.

O termo historiografia brasileira é muito amplo e impossível de esgotamento nesta discussão. Dessa forma, esclarecemos que o que denominamos de historiografia brasileira sobre a Reforma Protestante aqui é, primeiramente, as principais obras clássicas que foram traduzidas para a língua portuguesa e adjetivadas como principais em função da ampla difusão e uso delas na academia: Weber (2004), Delumeau (1989), Chaunu (1975), Elton (1982) e Febvre (2012). Ainda que seja complicado classificar autores internacionais como historiografia brasileira, tomamos o termo de empréstimo pelo fato desses autores, uma vez traduzidos, serem consolidados nas pesquisas brasileiras para definições prévias e definitivas de conceitos pertinentes a este tema. Sustentamos a afirmação que eles são os principais autores quando verificamos a presença deles na bibliografia básica dos ementários atuais dos departamentos de História das maiores universidades do País, incluindo aí a Universidade Federal de Goiás (UFG), a Universidade de São Paulo (USP) e a Universidade de Brasília (UnB).

Em segundo lugar, denominados de historiografia brasileira sobre a Reforma Protestante a publicação de resultado de pesquisas em artigos, teses e dissertações. Por exemplo, na escrita deste, acessamos o sítio eletrônico de periódicos da Capes, e inserirmos na busca, entre aspas, o termo Reforma Protestante, encontrando, como resultado (em 
língua portuguesa, no período entre 2016 e 2018, dado que é o período que compreende o ano de comemoração dos 500 anos da Reforma Protestante, com um ano anterior e outro posterior) onze textos publicados (artigos) e, neles, a persistência do conceito de Reforma Protestante usado concretamente, sem problematização. Quando fizemos o mesmo no Catálogo de Teses e Dissertações da Capes, ao refinarmos a busca na área de História, encontramos somente dois resultados, estando entre os mais atuais, uma dissertação e uma tese, ambas de 2011.

O conceito de protestantismo

O conceito protestantismo para se referir aos cristãos que não eram católicos a partir do cisma permanente do século XVI surgiu de forma espontânea na dieta de Worms em 1521, quando esta emitiu um decreto condenando Martinho Lutero como um herege perigoso. As dietas, do alemão reichstag, eram as assembleias políticas do Sacro-Império Romano Germânico. Desde 1521, portanto, todos os príncipes que apoiassem Lutero, contrariando com isso a decisão da supracitada dieta, seriam condenados com severas punições. Porém, como o imperador Carlos V (1500-1558) - que liderava as dietas e era fiel a Roma, tanto pelo cargo que ocupava como por sua ligação com a Espanha - estava ocupado com outras questões, não teve como fiscalizar a execução desse decreto, que foi ignorado até 1526, quando príncipes católicos exigiram seu cumprimento na primeira dieta de Espira, alegando que o movimento luterano, por ser questionador da Cristandade até estão estabelecida, estava provocando desordem social.

Após a segunda dieta de Espira, em 1529, seis príncipes alemães que tinham adotado o luteranismo deram entrada em um processo formal contra a proibição imperial dos príncipes apoiarem Lutero e, por essa ação, ficam conhecidos como príncipes protestantes. A Igreja Católica, aos poucos, passou a usar o termo para designar todos os seguidores das novas ideias, primeiramente para se referir aos luteranos, mas, em seguida, também agrupou no mesmo termo os demais seguidores dos diversos líderes, conforme apresentamos logo abaixo. Movimentos questionadores, inicialmente independentes, através de publicações, viagens individuais de envolvidos e troca de correspondências entre os líderes foram, aos poucos e no período seguinte, tomando consciência de um movimento de alguma forma alinhado. 
O conceito passou a ser usado pelos próprios questionadores a partir da reação católica, quando eles viram que seria necessário ignorar suas diferenças para enfrentarem uma ameaça comum, daí passarem, os próprios reformadores, a chamarem-se de protestantes. O termo serviu de elo para unir os diferentes movimentos questionadores da Igreja Católica espalhados pela Europa naquele momento e até hoje é usado justamente para tentar unir um grupo tão heterogêneo.

Inicialmente, luteranos no norte do Império, e zwinglianos na Suíça, não tinham consciência de que seus questionamentos eram duas faces de uma mesma moeda. Essa tentativa de conciliar todos os movimentos em uma corrente de pensamento uníssona, que seria conhecida retrospectivamente como nascimento do protestantismo, foi sendo construída paulatinamente pelos reformadores que contavam com apoio oficial. Com isso, percebe-se porque a identidade do cristão protestante é, até hoje, justamente a de não ter uma identidade única, pronta e definida, mas estar sempre em mutação, permitindo abarcar dentro de um mesmo conceito diferentes crenças e práticas religiosas. Esse foi o seu início. Daí que, se não há só luteranos, Lutero não pode ser considerado o pai ou fundador do protestantismo, mas um dos seus fundadores, em pé de igualdade com seus contemporâneos, que originaram toda a ramificação.

Percebemos que esses movimentos, que passaram a ser chamados de protestantes, quando analisados numa perspectiva posterior, se dividiram em duas grandes correntes: A denominada reforma magisterial e a denominada reforma radical, que, por sua vez, se subdividiram em três grupos. Do lado magisterial: Os luteranos - que são os seguidores de Martinho Lutero (1483-1546) e Phillipe Melanchton (1497-1560); os reformados - que são os seguidores de Zwínglio (1484-1531), Calvino (1509-1564) e Knox (1514-1572); e os anglicanos - quando o rei Henrique VIII (1491-1547) formou a Igreja nacional na Inglaterra com apoio de teólogos como Tomás Cranmer (1489-1556) e William Tyndale (1484-1536). Do lado radical: Os racionalistas, seguidores de Karstaldt (1486-1541); os espiritualistas, seguidores de Thomas Müntzer (1489-1525); e os anabatistas, seguidores de Conrad Grebel (1498-1526) e Félix Manz (1498-1527). 
Reforma ou reformas?

O termo reformados, para designar os seguidores de Zwínglio, Calvino e Knox, e posteriormente aos anglicanos também, passou a ser usado a partir do Colóquio de Marburgo, em 1529, para designar a teologia que era diferente da luterana. A partir desta data percebeu-se que apesar dos movimentos terem em comum o questionamento político e teológico da Igreja Católica e a desobediência a autoridade papal, principalmente enquanto normativa de fé, tinham sido construídas duas teologias distintas, cujas especificidades fogem ao nosso objeto neste momento.

A doutrina luterana foi então resumida no documento escrito por Phillipe Melanchton (1497-1560), A Confissão de Augsburgo, de 1530, enquanto a doutrina chamada de reformada resumiu a teologia de Calvino, Zwínglio e Knox no documento Catecismo de Heidelberg, de 1563, que depois foi revisto na Confissão de Westminster de 1646 . Enquanto os anabatistas, bem mais heterogêneos, tentaram resumir a sua doutrina na Confissão de Schleitheim, de 1527. Esse tripé de documentos teológicos tem sido as certidões de nascimento das principais denominações protestantes até hoje, tendo em vista que a igreja luterana baseia-se na Confissão de Augsburgo, enquanto as igrejas presbiterianas e anglicanas baseiam-se na Confissão de Westminster, e as igrejas batistas e metodistas baseiam-se, ainda que indiretamente, na Confissão de Schleitheim.

Foi, portanto, o teólogo luterano Joachim Westphal (1510-1574) quem passou a denominar de calvinista a doutrina oficial que vinha do sul do continente e que diferia dos luteranos, cuja doutrina tornara-se oficial em determinados principados ao norte. 0 problema, portanto, foi quando o príncipe Frederico III (1515-1576), eleitor palatino do Reno, em 1563, converteu-se do luteranismo para o calvinismo. Westphal o chamou de calvinista para estigmatizá-lo como uma espécie de traidor que estava preferindo adotar uma teologia que vinha de fora do Império. De fato, Frederico III preferiu adotar a doutrina do Catecismo de Heidelberg à Confissão de Augsburgo.

Portanto, os termos protestante, luterano, calvinista ou anabatista tiveram a mesma origem: Foram cunhados pelos inimigos. Dessa forma, os próprios seguidores da Confissão de Westminster, como os presbiterianos, preferem, até hoje, serem chamados de reformados, pois vêm no termo calvinista um pejorativo, ao passo que os luteranos preferem ser chamados de evangélicos. Os anabatistas, ao contrário, não se importam com 
o termo. Na busca de evocar uma tradição que os legitime, há até os que preferem usar o termo com certo orgulho, pois associar correntes protestantes aos reformadores perseguidos do século XVI não deixa de ser uma atrativa forma de legitimação. É interessante, também, como que, além de inventar uma tradição, o uso do conceito permite conferir status social ao grupo, já que, atualmente, luteranos, presbiterianos, anglicanos e batistas preferem usar o termo protestantes para, com esse uso, demonstrarem diferenciação - e até certa superioridade qualitativa e teológica - dos evangélicos pentecostais. Suposta superioridade que é construída e legitimada justamente pela tradição histórica, que os pentecostais não priorizam.

Junto ao problema de utilizar-se o termo Reforma Protestante, no singular, para definir uma gama de reformas diferentes, soma-se o problema de chamar toda a ação posterior da Igreja Católica, de dimensões continentais, de contrarreforma, como se tudo tivesse sido feito como reação aos novos protestantes. Não é porque algumas ações foram cronologicamente posteriores ao movimento luterano que elas constituíram uma reação. 0 conceito de contrarreforma passa a impressão de que a Igreja Católica estava inerte a tudo que estava acontecendo no século XVI e só quando supostamente se viu acuada e ameaça por Martinho Lutero, Calvino, e outros reformadores - o que dificilmente aconteceu - é que ela resolveu agir. A Igreja Católica tinha séculos de experiência para lidar com questionamentos e elaboração de pensamos contrários aos seus, o que nos faz ter sérias dúvidas quanto ao medo que ela teve da ameaça que realmente se constituiria a Reforma Protestante no seu embrião.

Antes de Lutero publicar suas 95 teses já havia o desejo interno de reformar a Igreja. O papa Júlio II (1443-1513), que comandou a Igreja de 1503 a 1513, convocou o V Concílio de Latrão (1512-1517), entre outros motivos, com esse intento. O bispo Egídio de Viterbo (1472-1532) discursou em sua abertura que se a Igreja não estabelecesse limites para a imoralidade do clero, a Cristandade acabaria. Isso foi levado em consideração, e vários movimentos de penitência foram promovidos. O diferencial, em parte, é que aquilo que o movimento católico considerava uma renovação, os reformadores consideraram que era o que precisava ser abolido: a salvação da alma do crente não estaria em mais obras de penitência, mas na aceitação da graça divina. Discussão, inclusive, que se antecedia a Lutero em séculos. 
Os teólogos católicos, como o pregador Jerônimo Savonarola (1452-1498), na Itália, e Francisco Ximenes de Cisneros (1436-1517), na Espanha, quiseram mudar atitudes. Lutero quis mudar a teologia por trás das atitudes. Para isso, resgatou antigos debates teológicos. Na Itália, a espiritualidade leiga se expressou nas confrarias conhecidas como oratórios, que se concentravam em obras de caridade. O oratório de Gênova, por exemplo, se concentrou em manter hospitais. Foram criadas as ordens dos teatinos e dos capuchinhos. Enfim, o século XVI europeu foi de uma efervescência intelectual gigante que se reduz quando se usa um conceito que reduz toda essa discussão.

É fato que esses movimentos, porém, foram pequenos e tardios para salvar a unidade da Cristandade sob Roma. O V Concílio de Latrão (1512-1517) acabou por colocar fim ao conciliarismo, reafirmar o poder papal sobre os territórios, indo na direção contrária do que o movimento, com a ascensão da burguesia, desejava. Com a morte de Júlio II, foi eleito Leão X (1475-1521), que governou de 1513 a 1521, continuando a política do anterior. Em 1521 assumiu o papa Adriano VI (1459-1523), doutor em Teologia, com o compromisso de reformar a cúria. A reforma da Igreja era sua bandeira, mas seu pontificado acabou cedo. A partir de 1523 foram eleitos sucessivamente Clemente VII (1523-1534), Paulo III (15341549) e Júlio III (1549-1555).

Paulo III tinha simpatia pelos humanistas, e nomeou uma comissão de 9 cardeais para estudar uma reforma para a Igreja. O relatório que a comissão produziu identificou vários problemas, como imoralidade clerical, nepotismo, simonia e abuso de poder. Quando os protestantes tomaram conhecimento do relatório, tiveram certeza que suas ações estavam no caminho certo. Ser católico, luterano ou reformado não significa necessariamente inimizade. Alguns católicos viam os protestantes com certa simpatia, ainda que escolhessem permanecer na Igreja romana. Foi o caso do movimento evangelização italiana, que vigorou de 1512 a 1560, que defendia a reforma da Igreja por meio da reforma individual por meio do estudo bíblico. A teologia que pregavam era muito parecida com a teologia da justificação pela fé luterana.

Paulo III talvez tenha sido o primeiro papa da denominada Contrarreforma católica. Pelo menos, por meio de ações concretas, foi o que mais enfatizou a tentativa de eliminar o protestantismo. Até porque, no seu pontificado é que a cúria romana se deu conta da seriedade e do tamanho do movimento protestante. Foi ele quem promulgou o Index: Índice 
de livros proibidos, a Inquisição moderna, a aprovação da criação da Companhia de Jesus por Inácio de Loyola e a convocação do Concílio de Trento (1545-1563). Esses quatro foram as principais ações do que a historiografia denominou de Contrarreforma católica. Essas ações talvez estivessem mais ligadas à novidade das novas terras encontradas do que às ações de Lutero.

É justamente por estar sempre em mudança e ser tão heterogêneo que os historiadores europeus e estadunidenses estão sempre revendo o tema da Reforma Protestante. Cada caricatura do movimento que é popularizada é criada a partir do grupo ao qual um autor pertence. Quando o pesquisador é um reformado, tende a exaltar Calvino acima de Lutero, apresentado este como um intolerante, antissemita, e aquele como um intelectual acima de interesses pessoais. Quando o autor é luterano, tende a apresentar Calvino como um beberrão, enquanto Lutero, um paladino da verdade lutando contra os baderneiros anabatistas.

O Brasil, onde o número de protestantes tem crescido consideravelmente nos censos oficiais, não tem acompanhado essa discussão. Se, em 2017 foi o ano dos 100 anos da Revolução Russa, e 500 anos da Reforma Protestante, é estranho que, no mesmo período, a busca no site de periódicos da Capes encontre 8 artigos para Reforma Protestante e 27 para Revolução Russa, além de que, nota-se que as pesquisas brasileira, salvo raras exceções, ainda vivem majoritariamente dos respingos de pesquisas anglo-saxãs através da tradução de obras antigas e às vezes até já superadas.

\section{Reforma ou cisma?}

Como vimos, o conceito acadêmico de Reforma Protestante remete, imediatamente, à ação do monte agostiniano Martinho Lutero, quando este se revoltou contra o papado, principalmente publicando suas 95 teses em 31 de outubro de 1517 em Wittenberg. Assim, o conceito de Reforma Protestante já está consolidado e traz implícito em si o recorte espaço-temporal do Sacro-Império Romano-Germânico entre 1517 a 1555. No entanto, apesar de ser um conceito bastante consensual, o termo Reforma Protestante traz consigo um juízo de valor implícito, ao afirmar que uma forma de cristianismo supostamente ruim, o católico, foi substituído por uma forma de cristianismo supostamente qualitativamente melhor, o protestante. 
O termo católica, referindo-se à Igreja da Idade Média ou do período da Reforma Protestante, pode ser entendido como anacrônico porque só foi estabelecido definitivamente como conhecemos hoje no Concílio de Trento (1545-1563). Antes do cisma luterano só havia uma Igreja, chamada assim e identificada muitas vezes como Igreja de Roma ou Igreja Romana, por causa da sua sede naquela cidade. Por outro lado, isso não impossibilita o seu uso para o período que estamos trabalhando, já que o termo catholicus no sentido de universal já era usado em documentos desde o Concílio de Niceia em 325.

Como alternativa, William G. Naphy (2008) prefere partir do impacto que as ações de Lutero causaram no Ocidente para conceituar a agitação do século XVI como A Revolução Protestante. Seja Reforma, seja Revolução, é certo que, enquanto conceitos, esses termos são um tipo ideal weberiano para permitir aos pesquisadores a possibilidade de se estudar o surgimento do protestantismo. Considerando esse debate, pressupomos que seria mais coerente denominarmos as ações dos agentes religiosos do período de cismas religiosos do século XVI europeu. Afinal, o termo cisma é o conceito usado para se referir ao surgimento da Igreja Ortodoxa no século XI (cisma oriental) e para referir-se ao período de disputa entre os papas de Roma e Avignon na Idade Média no século XIV (cisma ocidental). Por que, quando para se referir ao surgimento do protestantismo, a historiografia usa um conceito diferente do que foi usado para se referir ao surgimento dos ortodoxos cinco séculos antes? E, por que o conceito usado para o surgimento dos ortodoxos não traz o implícito juízo de valor de superioridade que o conceito usado para o surgimento do protestantismo carrega? Se a ação iniciada por Lutero é denominada de Reforma Protestante, a ação dos bispos do oriente no século XI deveria ser denominada de Reforma Ortodoxa e não Cisma do Oriente.

O conceito de Reforma Protestante foi cunhado em 1694 pelo historiador alemão Veit Ludwig von Seckendorff (1788) para explicar que no século XVI teve início um cristianismo não romano que modificou substancialmente a teologia até então predominante. Este novo cristianismo, como vimos acima, recebeu o nome de protestantismo porque seus adeptos protestaram contra a decisão da Dieta de Espira em 1529.

É preciso lembrar que Lutero e os demais reformadores não tinham consciência que suas ações dividiriam definitivamente a Cristandade posterior. Inicialmente não viam o fato de serem protestantes como significando que pertenciam a outra igreja diferente da 
Católica. Assim, partir do pressuposto de que os agentes históricos do século XVI tinham consciência de estarem propositalmente promovendo um cisma que permaneceria, como o conceito de Reforma Protestante ficou conhecido depois do século XVII, é incorrer em anacronismo. O que Lutero fez não foi fora da rotina. Era papel dos teólogos universitários elaborarem teses para serem debatidas. Lutero cumpria seu papel de professor universitário em busca de melhorar os problemas eclesiásticos que lhe eram contemporâneos.

A partir da obra de Seckendorff também que o conceito de Reforma ficou associado ao nome do monge agostiniano Martinho Lutero como protagonista. A historiografia alemã dos séculos XVIII e XIX então definia a Reforma Protestante como uma época iniciada com a publicação das 95 teses em 1517 em Wittenberg e caracterizada pela obra divinamente motivada de Lutero visando purificar a Igreja, e a Cristandade, de erros doutrinais. O terminus a quo da Reforma Protestante seria então a Paz de Augsburgo em 1555, quando um tratado foi assinado em 1555 na cidade de Augsburgo que estabelecia um acordo de trégua entre Carlos V e os príncipes protestantes seguidores da Reforma Luterana. A partir de então os luteranos passaram a ser tolerados no Sacro-Império Romano-Germânico. Depois, em 1839, o historiador alemão Leolpold Von Ranke (1844) popularizou o conceito de Contrareforma para definir a reação da Igreja Católica. Desde então, a historiografia protestante preferiu usar o termo Contrarreforma para se referir à ação da Igreja Católica, focando os movimentos contrários aos reformadores, inclusive com tentativa de detê-los, enquanto a historiografia católica preferiu usar o termo Reforma Católica para mostrar que a origem do termo estava no próprio catolicismo e era anterior à Lutero.

A longa tradição historiográfica construída pelos autores protestantes consolidou na academia a noção de que a Reforma Protestante ocorrida no século XVI teria sido um movimento exclusivo de purificação religiosa em resgate dos verdadeiros princípios do cristianismo contra os abusos do clero romano, principalmente na figura do papa. É claro que a incoerência entre o que era pregado e o que era praticado pela maioria do clero católico no período era gritante, mas, em contraste, essa historiografia tendeu a exaltar a figura de Lutero e Calvino como heróis que desafiaram gigantes, minimizando o contexto social, político e econômico, como se esses heróis fossem ascetas totalmente despossuídos de ambições ou interesses pessoais. Isso, inclusive, acabou ajudando a popularização da noção de que no século XVI as pessoas estavam desinteressadas da religião, o que não 
procede. O fato de as pessoas na Europa do século XVI estarem descontentes com o clero não significa que não tinham mais interesse pela religião. Pelo contrário, o desejo de reformar a Cristandade demonstra a importância que ela tinha para aquela mentalidade.

A historiografia católica, por sua vez, tentou diminuir ou refutar as críticas dos historiadores protestantes. Acusava-se a moral dos líderes proeminentes, colocava-se em dúvida as motivações dos agentes e responsabilizava os protestantes por terem dividido a Cristandade e, inclusive, serem os responsáveis pela tardia unificação alemã. Além disso, os autores católicos passaram a defender que as origens da reformação estavam no interior do próprio clero, com o movimento conciliarista, místicos e surgimento de novas ordens no período.

\section{Conclusão}

O movimento histórico denominado de Reforma Protestante seguiu o padrão de agentes históricos anteriores de questionar a teologia oficial da Igreja Católica e o poder do papa. Na Idade Média, quando agentes históricos assim o faziam, eram denominados de heréticos, e suprimidos pela Igreja. A Reforma Protestante não é estudada como uma heresia medieval, não só porque está cronologicamente fora do tempo entendido historicamente como medieval, mas porque ela não foi sufocada. Prevaleceu. Permaneceu. Inclusive com o protestantismo chegando ao dia de hoje. Então, se permaneceu, ao ponto de não ser classificado com o conceito de heresia, é um cisma na Cristandade oriental. Um cisma que, pelo protestante, é chamado de Reforma, pois reforme implica melhoria, e o protestante praticante entende que um cristianismo anterior, católico medieval, foi substituído por outro, que ele aderiu porque, para ele, é superior. Para um alemão positivista o termo também é pertinente, já que continua entendendo a ação do século XVI como mais um passo em uma evolução. Porém, vemos como um termo problemático para o historiador brasileiro do século XXI continuar fazendo uso.

Da mesma forma, o termo, no singular, não dá conta da dimensão das ações. Induz o leitor a pensar em termos menores do que realmente foi. Classifica equivocadamente determinados agentes como protagonistas, e outros como coadjuvantes, tornando o ponto de vista de alguns autores específicos, luteranos e presbiterianos, principalmente, como decisivos, e empobrecendo o debate entre historiadores, cujas perguntas são diferentes. 
Alguns conceitos tornam-se consagrados e a sua substituição é problemática. Dessa forma, esse texto é uma reflexão. Entendemos que um pesquisador não estará cometendo um erro se continuar utilizando o termo Reforma Protestante em suas pesquisas, desde que tenha ciência das suas limitações, e a traga junto à pesquisa. Por outro lado, seria interessante, ainda que paulatinamente, passar a denominar todos esses movimentos de cismáticos, ou os grandes cismas da cristandade, pela ordem cronológica que ocorreram: Primeiro cisma (século XI, com o surgimento dos ortodoxos), segundo cisma (século XIV, com a disputa entre dois - e três - papas na Cristandade ocidental) e terceiro cisma (século XVI, com o surgimento das grandes correntes questionadoras do papado comumente denominadas de reformadoras).

Explicando que, para ser um cisma, é necessário que o movimento questionador, ao contrário das heresias, que também eram questionadoras, tenha permanecido por um tempo considerável para promover mudanças sociais substanciais, sem sucesso da igreja romana em sufocá-las rapidamente. Então, ao nos referirmos ao terceiro cisma, também deveríamos usar o conceito no plural, cismas, para então darmos conta da pluralidade da movimentação daquele período. Dificilmente um conceito dará conta de abarcar toda a realidade que ele sintetiza. Essa insuficiência, porém, não descarta o seu uso. Pode-se usá-lo bem quando se conhece suas limitações.

\section{REFERÊNCIAS BIBLIOGRÁFICAS}

CHAUNU, P. O tempo das reformas. 1225-1550. II. A Reforma Protestante. Lisboa: Editorial presença, 1975.

DELUMEAU, J. Nascimento e Afirmação da Reforma. Tradução de João Pedro Mendes. São Paulo: Biblioteca Pioneira de Ciências Sociais, 1989.

ELTON, G. R. A Europa durante a Reforma. 1517-1559. Lisboa: Editorial Presença, 1982.

FEBVRE, L. Martinho Lutero, um destino. São Paulo: Três Estrelas, 2012.

NAPHY, W. G. The Protestant Revolution. From Martin Luther to Martin Luther King Jr. Londres: BBC Books, 2008.

RANKE, L. History of the Reformation in Germany. Philadelphia: Lea and Blanchard, 1844.

SECKENDORFF, V. L. Reformations Geschichte. Tübingen: Fues, 1788.

WEBER, M. A ética protestante e o 'espírito' do capitalismo. São Paulo: Companhia das Letras, 2004. 